$16^{\text {th }}$ International Congress of Metrology, 14006 (2013)

DOI: $10.1051 /$ metrology/201314006

(C) Owned by the authors, published by EDP Sciences, 2013

\title{
Strain fields measurement of non-rigid solid by scanning laser coupled with camera
}

\author{
Rahel RAHEL ${ }^{1}$, Yufei WANG ${ }^{2}$, Michael ROY ${ }^{2}$, Jean-François FONTAINE ${ }^{2}$ \\ ${ }^{1}$ DRIVE, Université de Bourgogne, route des plaines de l'Yonne, 89000 Auxerre, France \\ ${ }^{2}$ Laboratoire Electronique, Informatique et Image, route des plaines de l'Yonne, 89000 Auxerre, France
}

\begin{abstract}
Today, the techniques of measurement without contact by scanning laser are increasingly used. These techniques allow to measure 3D objects without contact and the measurement rates can reach few thousand points by second that is very adapted to complex shapes. To measure displacements and deformations, it is necessary to follow a solid particle in its motion between two configurations of the body before and after displacement. The method of stereovision based on grayscale patterns, obtained by applying a spray, is generally used. The results are obtained by two correlations: spatial and temporal correlations. An alternative method consists to use a scanner laser coupled with a camera. The laser scanner measures the 3D form and the camera permits to identify patterns on both configurations. The measurement process is described in the paper. The principle consists to acquire a point cloud of the surface before and after the movement as well as an image of the region of interest. The points clouds are given in the 3D frame and the position of pattern can be given in 3D coordinates. To have a coherent measurement, the camera and the laser scanner must be calibrated in the same frame using a single target. The difficulty is that the target must have contrast elements that are useful for calibrating the camera, but the response of the laser sensor is biased at a change of contrast. So, filtering must be used. Different kinds of targets have been tested (cube, checker board,...). The patterns are correlated in the images pair by classical correlation function. The point cloud is meshed with triangles (STL format) and projected on the corresponding image. On each image, the belonging of a pattern to a triangle is then tested on the basis of barycentric coordinates and the coordinates of the 3D pattern are calculated on the base of the conservation of these coordinates. So the localization of the pattern in 3D frame is possible. The advantage of this method is to reduce the imprecision of matching the search pattern unlike stereovision where two pairing are carried out. An application of deformation of soft body illustrates this approach. A comparison of the result is carried out with the stereo-correlation technique.
\end{abstract}

\section{Introduction}

Optical methods are currently used in mechanical experimentation. The most important techniques are photoelasticity [1], geometrical Moiré and Moiré's interferometry [2], Holography [3], speckle interferometry [4], grid method [5] and digital image correlation (DIC) [6]. These techniques are various and have, in most cases one particular application field.

Photoelasticity is an old technique [7]. It is based on the birifringence property of the studied middle. It is often limited to a bidimensionnal analysis $2 \mathrm{~d} 2 \mathrm{c}$ (2 dimensions/ 2 components or plane strains of plane surfaces). Due to recent progress, it can be applied to $2 \mathrm{~d} / 3 \mathrm{c}$ measurement (2 dimensions/3 components or planes stresses of 3D surfaces) [8]. With the optronics progress, this technique is now automated [9]. It allows determine the stress field at the surface (hydrostatic pressure) with a constant, which can be determined by a

\footnotetext{
a Jean-François FONTAINE: jffont@iut-dijon.u-bourgogne.fr
}

condition of nullity of ea free stresses edge. This principle and this inconvenient is to use polarized light and so to have a complex analysis.

The grid method, known on the name of Moiré's method is also an old technique that has a great development today [10]. It is applied in the context of measuring small displacements because the analysis on an impaired grid becomes difficult.

Other techniques are also very accurate as holographic interferometry or speckle interferometry (ESPI) [11]. They allow for measurements of the order of a few nanometers without necessarily needing to have a special preparation of the surface unlike the grid technique. However, for large deformations the signal is subjected to nonlinearities which are difficult to exploit. They are therefore limited to the measurement of small strain.

Finally, methods based on digital image correlation (DIC) complement these above techniques. The works of 
Chu et al. [12] have been precursors of many developments and improvements in particular using subpixel patterns correlation introduced by Sutton et al . [13]. This this can be carried out for no-classical measurement like mineral [14]. They have the advantage of being easily implemented whether in $2 \mathrm{~d} / 2 \mathrm{c}$ [15] or in $2 \mathrm{~d} / 3 \mathrm{c}$ by stereo-vision [16].

These methods are varied in their ability to measure against criteria such as spatial resolution, field size measurement, measurement in $2 \mathrm{D}$ or in $3 \mathrm{D}, \ldots$ Their application field can be summarized by the graph given in Figure 1.

Figure1. comparison of techniques for strain fields measurement (from [17])

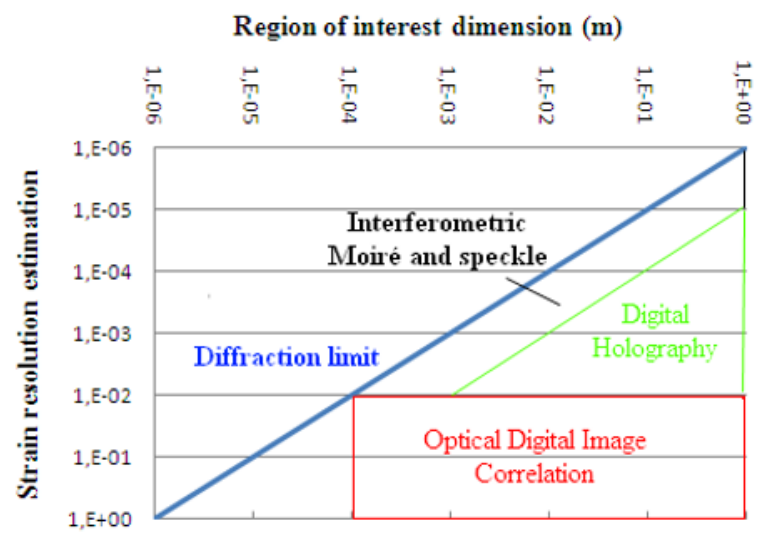

The method of digital image correlation (DIC) is probably one of the most commonly used, and many applications can be found in [18]. Different works on 2D measurement uncertainties were carried out. They aim to compare the different treatments made during a matching depending on the size of the pattern, grid, interpolation... Evaluated displacements are compared with the exact imposed values from virtual image and errors are statistically analyzed. Results show general trends rather independent of the implementations but strongly correlated with the assumptions of the underlying algorithms. In the case of the measurement of displacement fields and strains $(2 \mathrm{~d}, 3 \mathrm{c})$ from the coupling of the stereo-correlation, no such study has been conducted to our knowledge. The matching is then carried out at two levels (geometric and temporal) which increases the measurement inaccuracies

When only one camera is used, the DIC method can give only a displacement field in a plane parallel to the image of the observed object. The originality of the method proposed in this paper is to get the $3 \mathrm{D}$ coordinate through a sensor laser sheet and perform matching in a camera. The scanner gives 3D shape of the external object and the camera keeps track of the material particles to the surface of the observed object. The coupling of a CCD camera and a 3D laser scanner to obtain a 3D surface and the image associated to an object is presented.

\section{Camera calibration}

In this section, we explain how to calibrate the camera in order to evaluate its internal and external parameters. The intrinsic parameters contain informations about focal length, image format, and principal point. The extrinsic parameters give informations about the position of the camera, and give the transformation from the 3D world coordinates to the $2 \mathrm{D}$ camera coordinates. These parameters will be used later in this article to register the image from the camera with the $3 \mathrm{D}$ mesh from the laserrange scanner. There exist several methods to do the camera calibration [20] [21]. These methods assume a geometric pin-hole system. The Bouguet's method [22] is carried out to compute the camera parameters. First, a flat checkerboard pattern is used as a reference plane. Then approximately 20 pictures of the checkerboard are taken with the camera (see Figure 2). In our setup, the camera is in a fixed position, and the checkerboard is moved.

Figure 2. Checkerboard pattern images captured with the camera

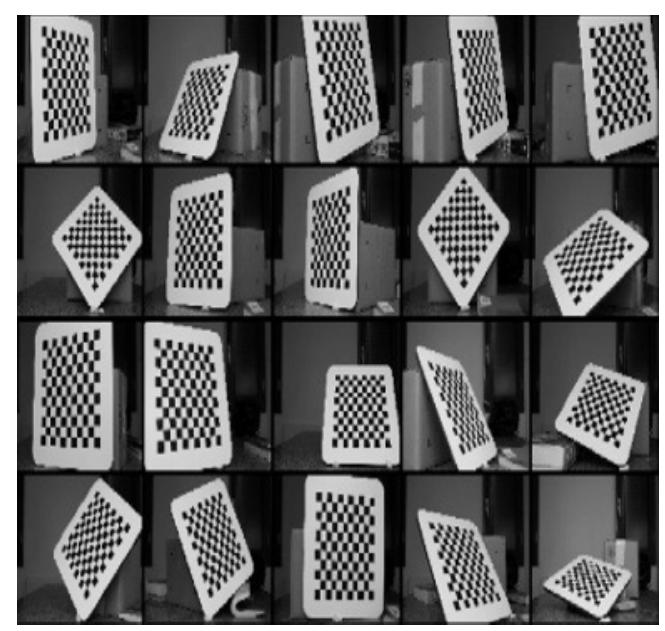

Bouguet has developed a camera calibration toolbox for Matlab ${ }^{\circledR}$, which makes it easy to compute camera parameters. It requires the checkerboard images, and some user interactions to guide the corner extraction process. After the computation, the program gives the different camera parameters, reprojection errors, and image deformation estimation. The camera transformation matrix Mc can be computed as the product of the intrinsic parameters matrix I and the extrinsic parameters matrix $E$

$$
\begin{aligned}
M_{c}=I_{c} \cdot E= & {\left[\begin{array}{llll}
m_{11} & m_{12} & m_{13} & m_{14} \\
m_{21} & m_{22} & m_{23} & m_{24} \\
m_{31} & m_{32} & m_{33} & m_{34}
\end{array}\right]=} \\
& {\left[\begin{array}{cccc}
\alpha_{u} & 0 & u_{0} & 0 \\
0 & \alpha_{v} & v_{0} & 0 \\
0 & 0 & 1 & 0
\end{array}\right] \cdot\left[\begin{array}{cc}
R_{3 \times 3} & T_{3 \times 1} \\
0 & 1
\end{array}\right] }
\end{aligned}
$$

Where $\alpha_{u}$ and $\alpha_{v}$ are scale factors, $\mathrm{u}_{0}$, and $\mathrm{v}_{0}$, coordinates of principal point (intrinsic parameters), $R_{3 \times 3}$ and $T_{3 x l}$, rigid Camera/Image transformation (rotation and translation). The $M_{c}$ matrix gives the transformation from a $3 \mathrm{D}$ point in the world coordinate system to the corresponding $2 \mathrm{D}$ point in the camera coordinate system. 


\section{Laser range calibration and registration}

In this section, we explain the laser-range scanner calibration process, and the registration of the camera image with the scanner point cloud. First we need to calibrate the laser-range scanner in order to compute the transformation from the 3D world coordinate system to the $3 \mathrm{D}$ scanner coordinate system. We use the same flat checkerboard pattern as before. This allows us to define the same reference frame between the camera and the laser-range scanner (see Figure 2).

Figure 3. Reference frame on the checkerboard pattern shared by the camera and the laser-range scanner.

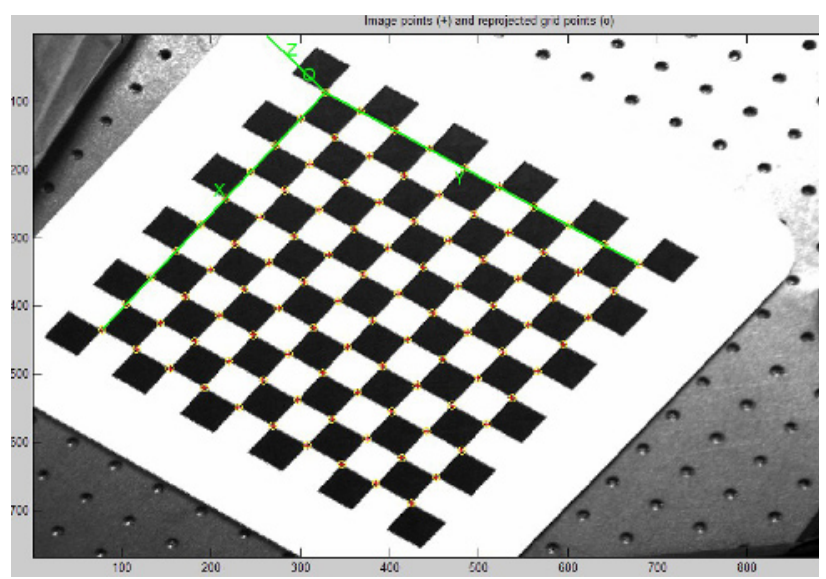

First an acquisition of the checkerboard pattern with the laser-range scanner is carried out. In Figure 4, we see the $3 \mathrm{D}$ point cloud of the checkerboard pattern given by the laser-range scanner. Note that the laser-range scanner only acquires points in the white areas of the checkerboard. This is due to the fact that the black areas do not reflect the light of the laser, so the scanner cannot acquire points. The only restriction is to make sure that there are enough acquired points on the corners of each square of the checkerboard.

Figure 4. 3D Checkerboard pattern captured with the laserrange scanner (in black: measurement point cloud - in blue: last mean square associated plane).

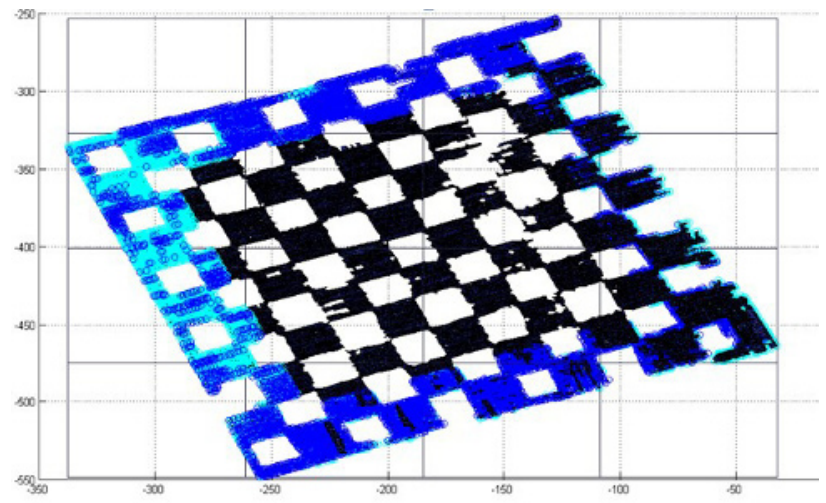

The second step consists of computing the reference frame on the $3 \mathrm{D}$ point cloud. Note that the reference frame is the same for the camera and the laser-range scanner. To do that, we compute a least square estimation of the plane to get the vector of the Z-axis (i.e. the normal vector of the checkerboard plane). The vector of $\mathrm{X}$-axis is estimated by manually selecting points. Then the vector of the $\mathrm{Y}$-axis is computed by the cross product of the Zaxis vector and the $\mathrm{X}$-axis vector. Now that the reference frame is defined, the transformation matrix $M_{s}$ is computed from the $3 \mathrm{D}$ world coordinate system to the $3 \mathrm{D}$ laser-range scanner coordinate system (see Figure 5).

Figure 5. World scanner and world camera transformation

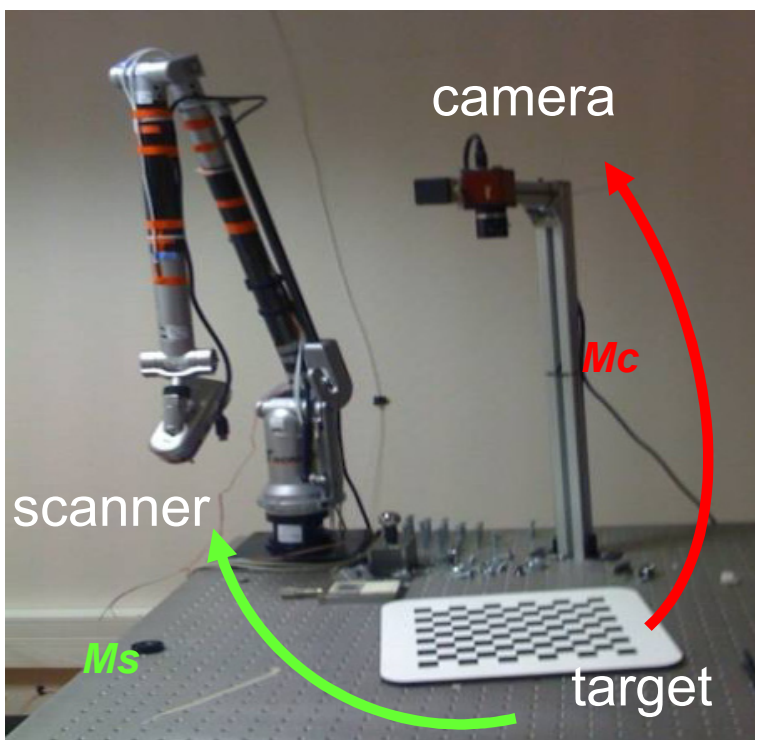

The last setup of our acquisition system is the registration of the laser-range scanner data with the camera data. The transformation matrix $M_{t}$ is computed by the product of the camera transformation matrix $M_{c}$ and the inverse of the laser-range scanner transformation matrix $M_{s}$ (see Equation 3).

$$
M_{t}=M_{c} \cdot M_{s}^{-1}
$$

The $M_{t}$ transformation matrix gives the corresponding $2 \mathrm{D}$ pixel of the image to any $3 \mathrm{D}$ point of the point cloud.

\section{Displacement and strain measurement}

After calibration of scanner in camera in CMM or measurement arm coordinates system, the object is scanned and an image is taken with the camera for the both configurations (before and after displacement). The point cloud is filtered to remove outlier points. Based on the curvature, cloud density is reduced so that the distance between 2 points is compatible with the size of the patterns planned to the pairing of both image (step1). Then, a STL meshes are built and regulated if necessary (step 2). The both Meshes are projected on the corresponding image (step 3). The patterns are mapped using correlation technique (step 4) and the patterns center are computed in the nodal coordinates (barycentric coordinates) of a triangular element. The belonging of the pattern centre to the element is tested with the barycentric coordinates (step 5). 3D coordinates are then calculated by assuming that the barycentric coordinates are kept in the passage from $2 \mathrm{D}$ to $3 \mathrm{D}$ (step 6). Finally, the 
displacement is obtained between the matched points in the $3 \mathrm{D}$ space and the strain can be calculated in using nodal interpolation function. The figure 6 illustrates the different steps of the data treatment.

Figure 6. Different steps of the data treatment.

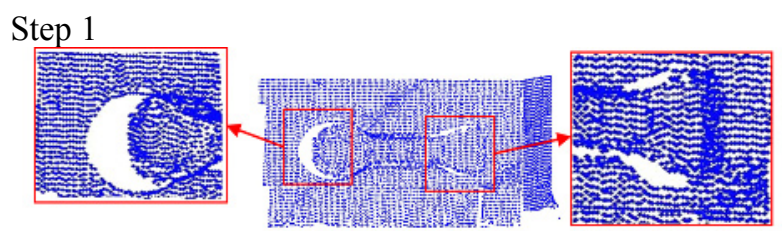

Step2

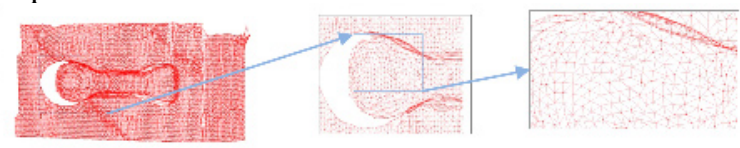

Step 3

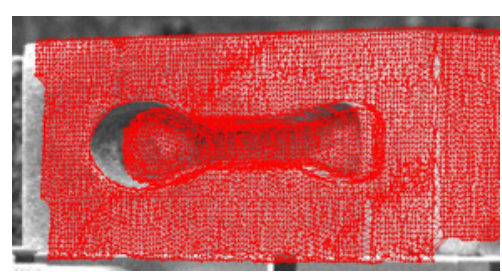

Step 4
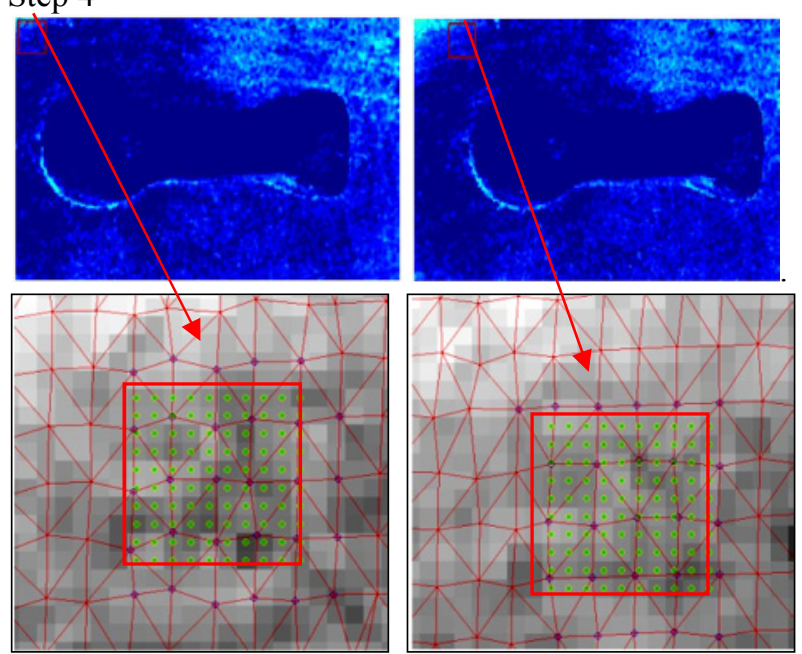

Step 5

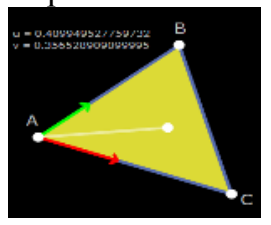

\section{Experimentation}

\subsection{Solid displacement measured with coupled CMM/laser scanner}

First experiments have been carried out with a laser scanner mounted on CMM [22] (see Fig.7). A solid prescribed displacement of $10 \mathrm{~mm}$ in the $\mathrm{X}$ axis CMM direction has been applied to a little spoon mould in medium (the medium is a good material giving Lambertian reflections). The displacement in different locations (flat skew surface portion or) has been measured (see Fig. 8) for different regions of interest (ROI) composed of a regular grid of 10x10 patterns.

The results are presented in table 2 . The values of the standard deviations for the whole ROI are between of $0.02 \mathrm{~mm}$ and $0.03 \mathrm{~mm}$. They are slightly higher for patterns located on a skew surface (pattern 2 and 3). They are lower along the $\mathrm{Z}$ axis which is perpendicular to the optical axis.

Figure 7. Scanner on $\mathrm{CMM}+$ camera

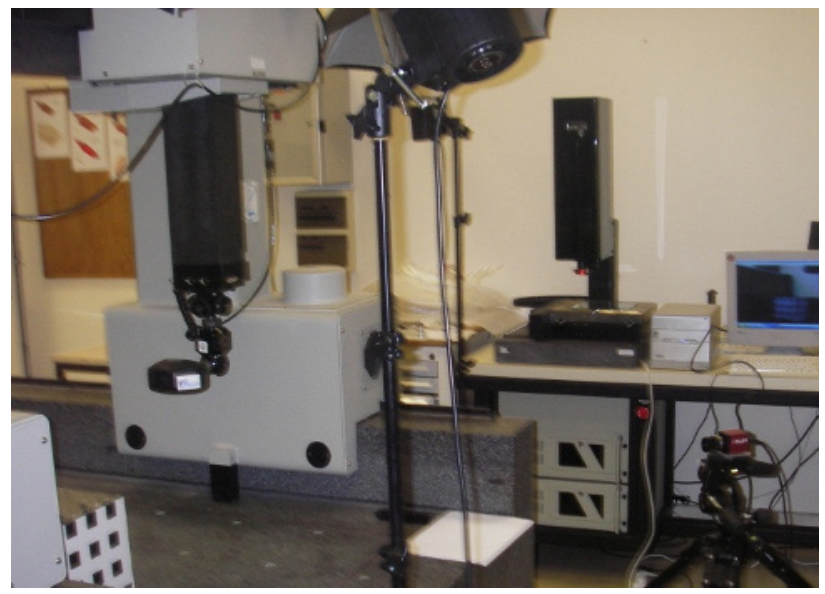

Figure 8. Location of some different patterns on the part

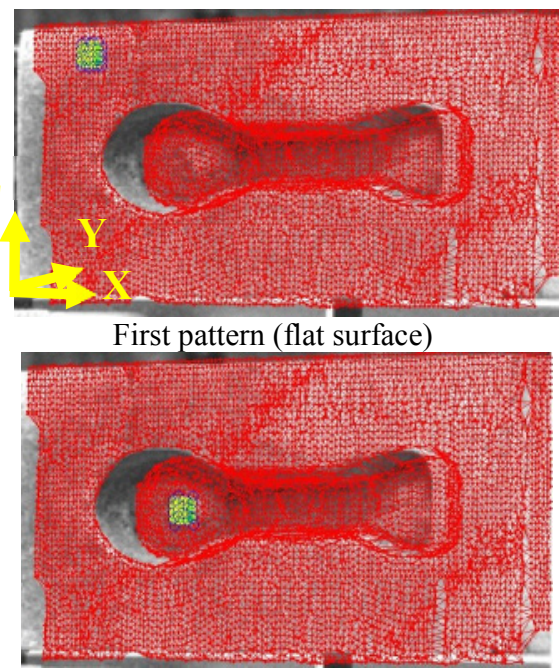

Second pattern (skew surface)

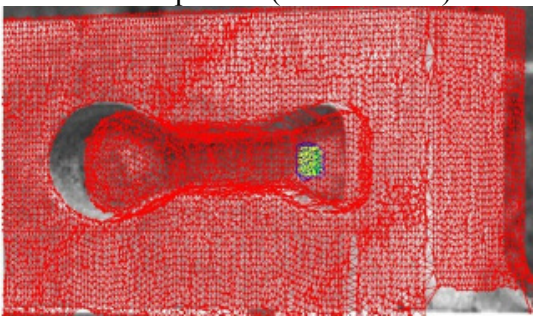

Third pattern (skew surface)

The results are presented in table 2 . The values of the standard deviations for the whole ROI are between of $0.02 \mathrm{~mm}$ and $0.03 \mathrm{~mm}$. They are slightly higher for patterns located on a skew surface (pattern 2 and 3). They are lower along the $\mathrm{Z}$ axis which is perpendicular to the optical axis. 
Table 2. Results for different ROI of a prescribed displacement of $10 \mathrm{~mm}$ in CMM X-Axis

\begin{tabular}{|c|c|c|c|c|c|c|c|c|}
\hline \multicolumn{7}{|c|}{ Displacement $(\mathrm{mm})$} \\
\hline & \multicolumn{2}{|c|}{ X-Axis } & \multicolumn{2}{|c|}{ Y-Axis } & \multicolumn{2}{|l|}{ Z- Axis } & \multicolumn{2}{c|}{$\begin{array}{c}\text { norm of the } \\
\text { motion vector }\end{array}$} \\
\hline No & $\begin{array}{c}\text { M.V } \\
(\mathrm{mm})\end{array}$ & $\begin{array}{l}\text { S.D. } \\
(\mu \mathrm{m})\end{array}$ & $\begin{array}{c}\text { M.V } \\
(\mathrm{mm})\end{array}$ & $\begin{array}{c}\text { S.D. } \\
(\mu \mathrm{m})\end{array}$ & $\begin{array}{c}\text { M.V } \\
(\mathrm{mm})\end{array}$ & $\begin{array}{c}\text { S.D. } \\
(\mu \mathrm{m})\end{array}$ & $\begin{array}{c}\text { M.V } \\
(\mathrm{mm})\end{array}$ & $\begin{array}{c}\text { S.D. } \\
(\mu \mathrm{m}))\end{array}$ \\
\hline ROI 1 & 10.005 & 23.4 & 0,020 & 21 & 0,005 & 8.2 & 10,002 & 24 \\
\hline ROI 2 & 9.992 & 26.6 & 0,012 & 22.9 & 0,002 & 8.2 & 9,995 & 26.9 \\
\hline ROI 3 & 9.983 & 23.8 & 0,011 & 23.8 & 0,008 & 8.3 & 9,990 & 27.9 \\
\hline
\end{tabular}

\subsection{Deformable tube in silicone measured with portable CMM}

A second test to characterize the measurement principle has consisted to measure a thin walled tube in silicone under internal pressure. The tube had the following dimensions: $20 \mathrm{~mm}$ of diameter, $2 \mathrm{~mm}$ of thickness and $200 \mathrm{~mm}$ of length (see Fig 9).

Figure 9. Scanner on portable CMM + camera

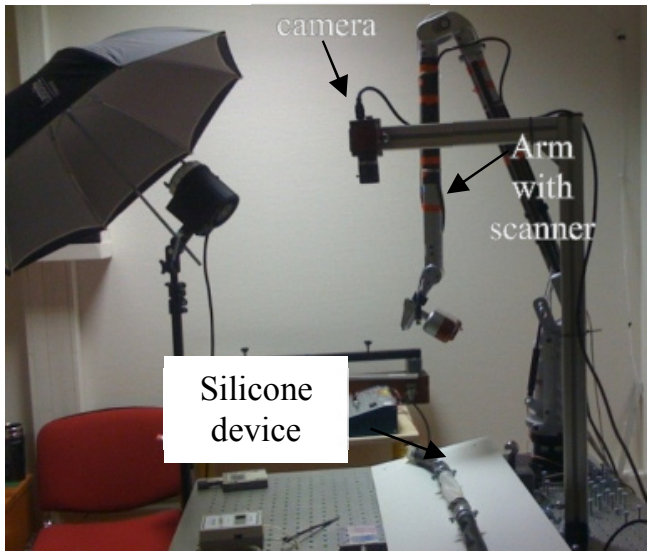

Different pressures at different level were applied by compressed air. Figure 10 shows the pattern grids and the associated meshes for two pressure levels $(1.5 \mathrm{kPa}$ and 7 $\mathrm{kPa})$

Figure 10. Pattern grid for different pressure levels and associated meshes

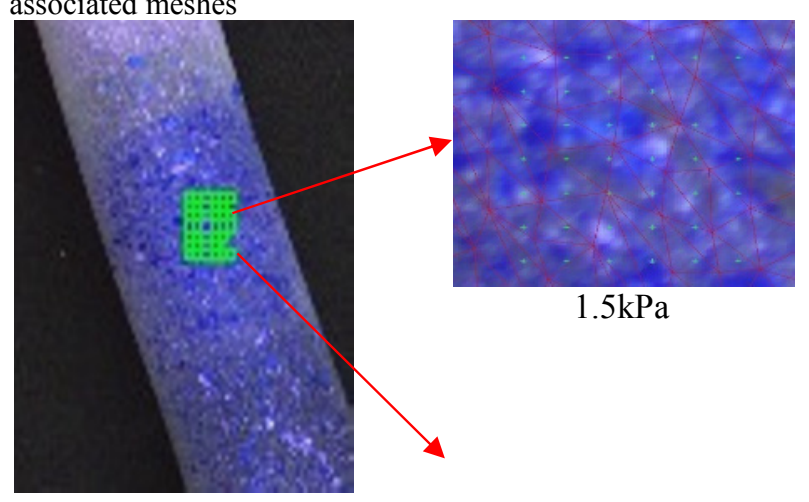

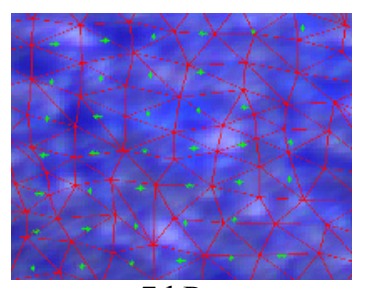

$7 \mathrm{kPa}$

The results found on 4 ROI constituted of 20 patterns (see Figure 11) have been compared with results measured simultaneously with stereo-vision system. One of both cameras of stereo-vision system has been associated to the scanner laser for limiting the variability. The results are given in table 3 . The results obtained with the two methods are much closed except for the first ROI. Some noise can come from the applied spray that can give specular reflections. When the pressure level increases, the gap between both methods decreases: the mean value of circumferential strain for stereo-vision reaches $3,8 \%$ and for scanning + camera 3,2\% with a standard deviation less than $0,6 \%$ for both methods

Figure. 11. Four different ROI of the silicone tube under pressure of $15 \mathrm{kPa}$

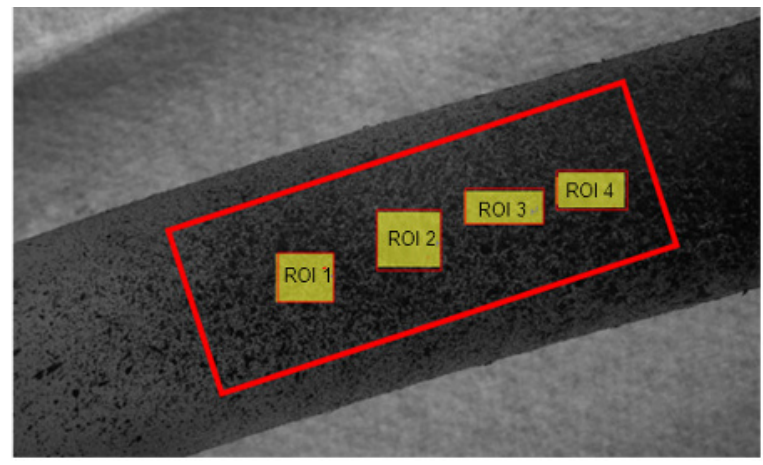

Table 3. Comparison of results obtained with laser scanned coupled with camera and stereo-vision system

\begin{tabular}{|c|c|c|c|c|c|}
\hline & \multicolumn{4}{|c|}{ Circumferential strain $\left(10^{-2}\right)$} & \multirow{3}{*}{$\begin{array}{l}\text { relative } \\
\text { difference } \\
\text { between } \\
\text { the two } \\
\text { methods }\end{array}$} \\
\hline & \multicolumn{2}{|c|}{ stereovision } & \multicolumn{2}{|c|}{ laser+camera } & \\
\hline & $\begin{array}{l}\text { Mean } \\
\text { value }\end{array}$ & $\begin{array}{c}\text { Std } \\
\text { Dev. }\end{array}$ & $\begin{array}{l}\text { Mean } \\
\text { value }\end{array}$ & $\begin{array}{c}\text { Std } \\
\text { Dev. }\end{array}$ & \\
\hline ROI 1 & 1,6 & 0,2 & 2,4 & 0,3 & $36.11 \%$ \\
\hline ROI 2 & 1,9 & 0,1 & 2,0 & 0,3 & $4.41 \%$ \\
\hline ROI 3 & 1,8 & 0,2 & 1,8 & 0,2 & $1.49 \%$ \\
\hline ROI 4 & 1,8 & 0,2 & 1,8 & 0,2 & $0.28 \%$ \\
\hline $\begin{array}{l}\text { Standard } \\
\text { deviation for } \\
\text { the mean } \\
\text { values of } \\
\text { whole ROI }\end{array}$ & 0.03 & $\mathrm{x}$ & 0.06 & $\mathrm{x}$ & \\
\hline
\end{tabular}

\section{Conclusion}

The presented work shows that it is possible to measure displacement field and so strain field with a scanner laser coupled with a camera. The scanner laser gives the $3 \mathrm{D}$ 
coordinates and the camera permits to follow the particle in its motion. When the scanner is controlled by a CMM with a currently measuring range of $1 \mathrm{~m}$, the measurement can be accurate in the order of $210^{-5}$. The result obtained with a measurement arm, the performance are slightly less good $\left(6.10^{-5}\right)$ but comparable to those obtained with a stereo vision system. The system is well suited when the measured objects have surfaces with strong curvatures which are well taken care of by the laser scanner.

\section{References}

1. Haake S.J., Patterson E.A., Wang Z.F., 2D and 3D Separation of stresses using automated photoelasticity. Experimental Mechanics, Vol. 36, 3,(1996), 269-276.

2. Olister G.S., Experimental stress analysis : Principle and method, pp 249.275 Cambridge University Press, 196.

3. Desse J.M., Picart P., Tankam P., Digital color holography applied to fluid and structural mechanics, Optics and Lasers in Engineering, vol. 50, pp. 18-28, 2012.

4. Françon M., Laser speckle and related phenomena, Information processing using speckle patterns, Topics in Applied Physics. Vol 9, chapt1975, Springer-Verlag.

5. Surrel Y., Moiré and grid methods in optics, SPIE, 2342 (1994) 213-220.

6. Sutton M.A., Cheng M., Peters W. H., Chao Y.J., McNeill, S.R., 1986. Application of an optimized digital correlation method to planar deformation analysis. Image and Vision Computing 4 (3) ,143-150.

7. WELLER R., Three dimensional photoelasticity using scattered light, J. Appl. Phys. 12, 610 (1941); http://dx.doi.org/10.1063/1.1712947

8. Lagarde A., Static and Dynamic Strain Measurement on a Plane Surface. Three-dimensional Photoelasticity, Proceedings of the IUTAM Symposium, Poitiers, France Aug $31^{\text {st }}-$ Sept $4^{\text {th }} 1998$.

9. Ajovalasit A., Petrucci G. et Scafadi M., Phase shifting photoelasticity in white light, Optical and Laser in engineering, vol. 45, (2007), 596-611.

10. Surrel Y., La technique de la grille pour la mesure de champs de déplacements et ses applications, Instrumentation mesure et métrologie, Vol 4/3-4 .2004 ,193-216.

11. Sjödahl M., Electronic speckle photography: increased accuracy by nonintegral pixel shifting, Applied Optics, Vol. 33, Issue 28, 6667-6673 (1994).

12. Chu T C, Ranson W F, Sutton M A, Peters W H. Applications of digital image correlation techniques to experimental mechanics. Experimental Mechanics, 1985; 25 (3),232-244.

13. Sutton M A, McNeill S R, Jang J, Babai M. Effects of subpixel image restoration on digital correlation error estimates. Optical Engineering, 1988; 27 (10), 870-877.

14. Hild F, Raka B, Baudequin M, Roux S, Cantelaube F., Multiscale displacement field measurements of compressed mineral-wool samples by digital image correlation. Applied Optics, 2002; 41 (32), 6815-6828.
15. Sutton, M. A., Wolters, W.J., Peters, W. H., Ranson, W.F., McNeill, S. R., Determination of displacements using an improved digital correlation method. Image and Vision Computing, 1 (3), 1983,133139.

16. Garcia D., Mesure de formes et de champs de déplacements tridimensionnels par stéréo-corrélation d'images, $\mathrm{PhD}$ Institut National Polytechnique de Toulouse, France, December 2001

17. Sutton M. A., Recent developments and trends in measurements from the macroscale to reduced length scales, Berthaud Y. et al. (eds.), in Proceeding of Colloque Photomécanique 2004, 4-6 Mai, p. 1-8.EMAC, France.

18. Bornet M., Bremand F., Doumalin P., Dupré J.-C., Fazzini M., Grédiac M., Hild F., Mistou S., Molinard J., Orteu J.-J., Robert L., Surrel Y., Vacher P., Wattrisse B., Assessment of digital image correlation measurement errors : Methodology and results. Experimental Mechanics, 49(3) (2009).

19. Faugéras OD., Toscani G., Camera calibration for 3-D computer vision, Proceedings of IEEE International Workshop on Machine Vision and Machine Intelligence, Tokyo, Japan, (1987)

20. Horaud R., Monga, O., Vision par ordinateur: outils fondamentaux, $2^{\text {nd }}$ edition Hermès(1995).

21. http://www.vision.caltech.edu/bouguetj/calib doc/ by Jean-Yves Bouguet Last updated July 9th, 2010

22. Rahel R., Roy M., Fontaine J.F.,, Mesure de champs de déplacements tridimensionnels par couplage caméra et capteur laser $3 \mathrm{D}$, in proceeding of colloque CMOI, 21-23 novembre (2008) Nantes, France. 